\title{
Effect of UV-radiation on physical properties for CR-39 detector
}

\author{
Qusay Kh. O. Al-dulamey \\ Department of Physics / Collage of Science \\ University of Mosul
}

Received

22 / 03 / 2010
Accepted

14 / 09 / 2010

\begin{abstract}
الملخص
تم في هذا البحث دراسة تأثير الأشعة فوق البزفهية على الخواص الفيزيائية (الامتصاص

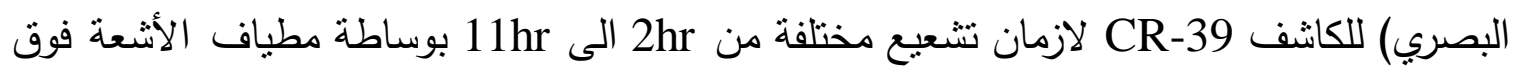

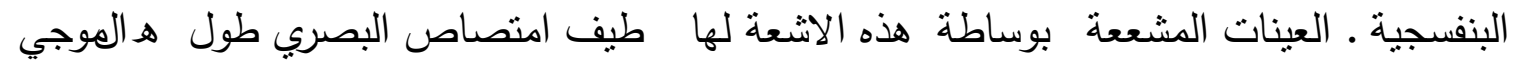
مابينnm (1110-190). بالقرب من nm 314-316 كان هنالك اعلى حالة امتصاص • من خلال طيف الأشعة فوق البنفجية نم ملاحظة تغير في حافة الامتصاص عند الأطوال الموجية العالية ،

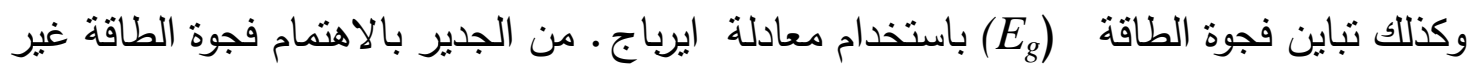

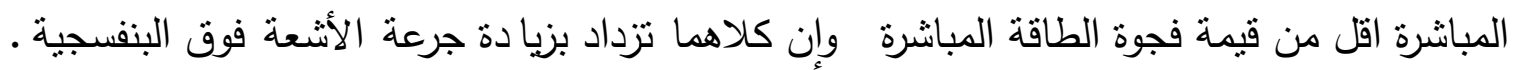
كما نم حساب عدد ذرات الكاربون (N) بالاعتماد على كل من فجوتي الطاقة المبانشرة وغير

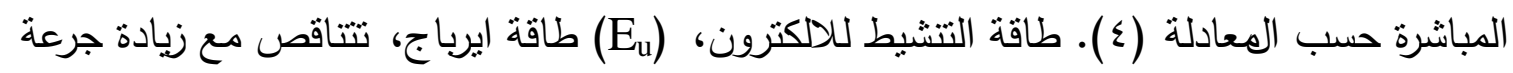
الاشعة فوق البنفسجية.
\end{abstract}

\begin{abstract}
In this work, several pieces of CR-39 detector were irradiated by UV radiation in order to study their physical characteristics. A UV spectrometer was utilized to read radiation coming out of the CR-39 detectors., and obtain their optical absorption. It was realized that the optical absorption wave length range was between 190-1110 nm. Near 314-316 nm at the absorption peak, a UV spectrum change was oserved in which there was an energy gap $\left(E_{g}\right)$ variation which was confirmed by the Urbach equation. It was interesting to notice that the indirect inergy gap value was less than that of
\end{abstract}


the direct gap value. Both direct and indirect energy gaps do increase with increasing dose of UV radiation. The number of carbon atoms (N) was calculated depending on direct and indirect energy gaps return to the equation (4).It was also observed that the excitation electron, Urbach energy $\left(E_{u}\right)$, do actually decrease when UV radiation dose is increased.

\section{Intruduction}

The absorption coefficient near the band edge for non-crystalline materials shows an exponential dependence on the photon energy (Urbach, 1953). The different batches of CR-39 were irradiated with various Ultraviolet (UV) sources and an excimer laser (lambda=308) and the visible change of color of defects under heavy dose appeared in both case studied by (Aburjared et al, 2000). The optical absorption coefficient $(\alpha)$ was calculated from the absorbance (A) Studied by (Mark, 2001). (Bozhko et $a l, 2002)$ found Urbach energy depend on the temperature which was generated from the band and the type material.The origin of $E_{u}$ is considered as thermal vibrations in the lattice-(Migahed \& Zidan, 2006). The effect of annealing in the optical absorbance of PM-355 nuclear track detector radiated by alpha particale studied from (Sulaiman, 2006). (Shamra et at, 2007) found the effect of gamma radiation on optical properties of CR-39 polymer with various dose $(20-800 \mathrm{kGray})$ and determined the values of indirect and direct for band energy gap..(Zaki, 2008) used gamma radiation to irradiate CR-39 and he found the optical band gap (direct and indirect) decreased with photon energy. The number of carbon atom and Urbach energy was determined. (Tse et al, 2008) studied the effect of UVC exposure on alpha- particle track parameter in CR-39 and find the track diameters and depths were used to drive a V function for CR-39 detector with and with out UV-radiation (Ramola et al, 2008) modified the optical band gap, carbonaious cluster and structure in CR-39 and PET polymers irradiated by $100 \mathrm{MeV} \mathrm{O}_{7+}$ ions ands found the UV-visible show the shift in the absorption edge towards the higher wave length indicating the change in band gap(Kumar et al, 2009) studied the effect of neutron radiation with optical properties of CR-39. He found the band energy gap for two case direct and indirect which was decreased with increased the fluences of neutron radiation and determined the Urbach energy, number of carbon atom. (Prasher et al, 2009) deals with the changes induced to CR-39 and PET polymers by IR irradiation. The modifications induced in the polymers due to IR irradiation have been analyzed with the help of XRD and UVvisible spectra of the pristine and IR irradiated polymers.

In the present work, we report the effect of UV-radiations on the UVVIS spectra of CR-39 plastic track detector as the spectroscopic studies. Also we investigated the behaviours of band gap and Urbach energy with 
increasing UV dose. The simultaneous existence of indirect and direct band gap in CR-39 polymer and the number of carbon atoms $(\mathrm{N})$ in a cluster are also reported.

\section{Experimental Procedure}

CR-39 samples of thickness $250 \mu \mathrm{m}$, type TASTRAK (Track Analysis System Ltd., UK) (composition $\mathrm{C}_{12} \mathrm{H}_{18} \mathrm{O}_{7}$, molecular weight 274 a.m.u., density $1.32 \mathrm{~g} / \mathrm{cm} 3$ ), were irradiated with different $\mathrm{UV}$ - radiation doses at $4 \mathrm{~cm}$ from the UV source has wave length $254 \mathrm{~nm}$.

The nature of the optical modifications of the UV-irradiated CR-39 polymer samples were subjected to spectral studies in the Ultraviolet and Visible region. These studies were carried out by using TECHCOMP Double beam Double monochromator UV-Visible Spectrophotometer (UVVIS 8500) in the wavelength range of 190-1110 $\mathrm{nm}$ having resolution of 0.1 $\mathrm{nm}$ (Zaki, 2008). All the spectra were recorded by mounting the samples in the Integrating Sphere Assembly attached with the Spectrophotometer, keeping air as the reference.

\section{Results and Discussion}

From these spectra, displayed in Fig. 1, it is clear that a shift of absorption edge towards longer wavelength with increasing UV- absorbed dose can be readily observed. The absorption peak with increasing dose is seen to change into a broad one. This behavior is generally interpreted as caused by the formation of extended systems of conjugate bonds i.e. possible formation of carbon clusters. The absorption bands in the investigated range of wavelength are associated to the $\pi_{-} \pi^{*}$ electronic transitions. This type of transitions occurs in the unsaturated centers of the molecules i.e. in compounds containing double or triple bonds and also in aromatics. The excitation of $\pi$ electron requires smaller energy and hence, transition of this type occurs at longer wavelengths. (Zaki, 2008).

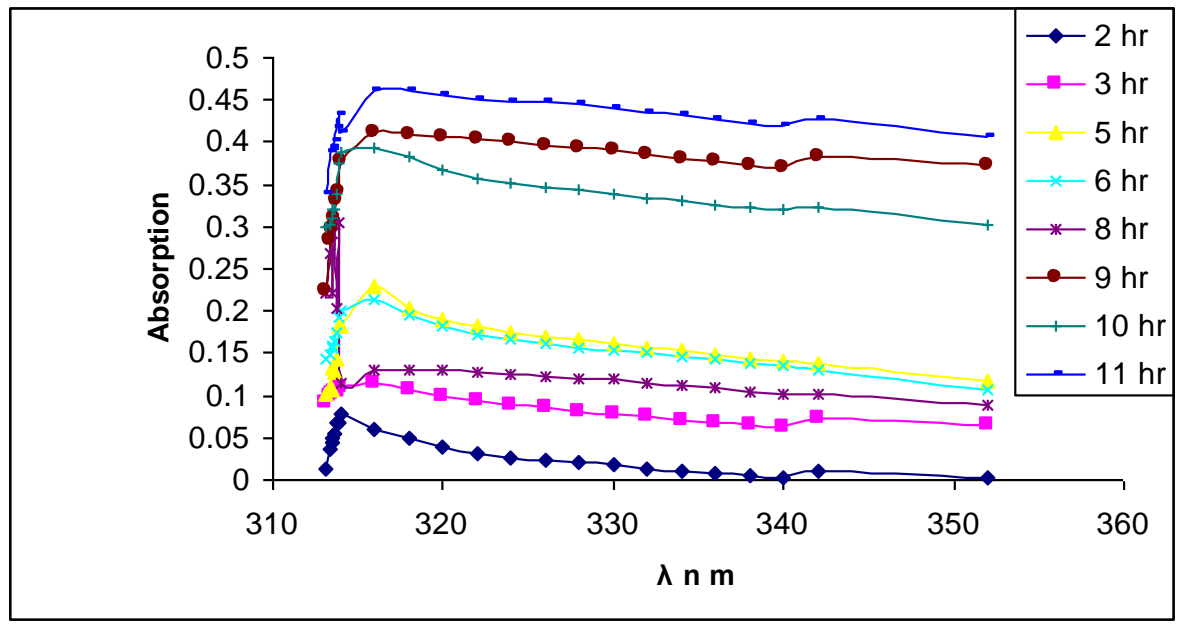

Fig. 1: UV-visible spectra of the UV -irradiated CR-39 
The optical absorption coefficient $(\alpha)$ was calculated from the absorbance, (A). After correction for reflection losses, may be obtained using the following equation (Mark,2001)

$\alpha(v)=2.303 \mathrm{~A} / \mathrm{t}$

where $\mathrm{t}$ is the sample thickness in $\mathrm{cm}$ and $\mathrm{A}$ is defined by $\mathrm{A}=\log$ (Io/I) where Io and I are the intensity of the incident and transmitted beams, respectively. The absorption coefficient near the band edge for noncrystalline materials shows an exponential dependence on the photon energy (hv) which follows the Urbach formula (Urbach,1953)

$\alpha(v)=\alpha_{o} \exp \left(h v / E_{\mathrm{u}}\right)$

where $\alpha_{0}$ is a constant, $E_{u}$ is called Urbach energy which is interpreted as the width of the tail of localized states in the forbidden band gap, $v$ is the frequency of radiation and $h$ is Planck's constant.(Migahed \& Zidan,2006)The logarithm of the absorption coefficient $\alpha(v)$ was plotted as a function of the (hv) for CR-39 irradiated with different doses of UV radiation as in Fig. (2 : a,b,c,d,e,f,g,h).

The values of the energy $\left(E_{u}\right)$ were calculated by taking the reciprocal of the slopes of the linear portion in the lower photon energy region of these curves and listed in Table 1. The decrease in the Urbach's energy in case of CR-39 may be due to the decrease in the crystalline nature of the polymer (Kumar et al,2009).

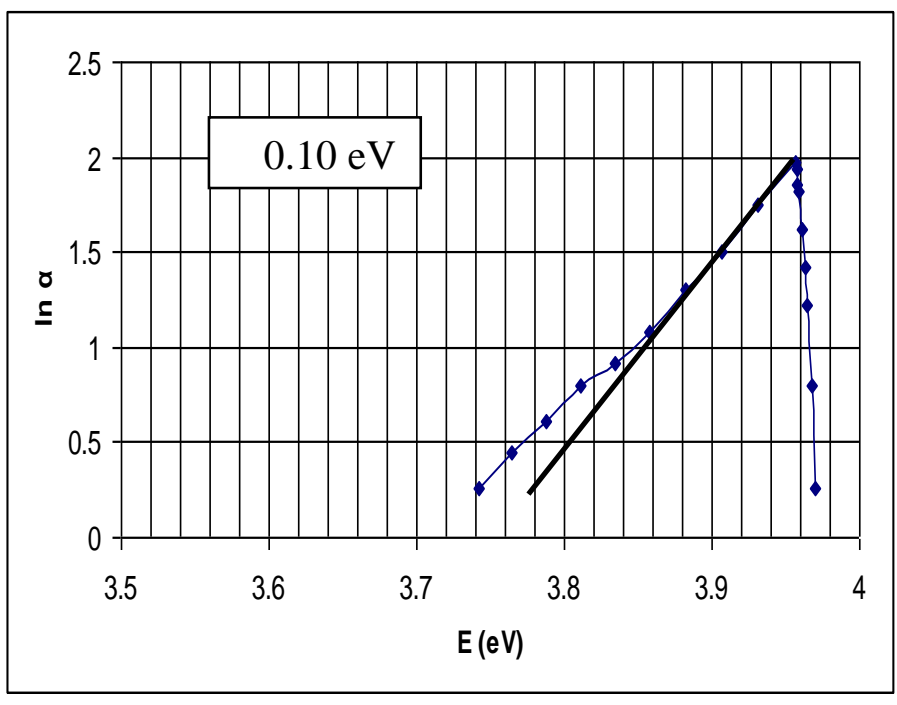

a $-2 \mathbf{h r}$

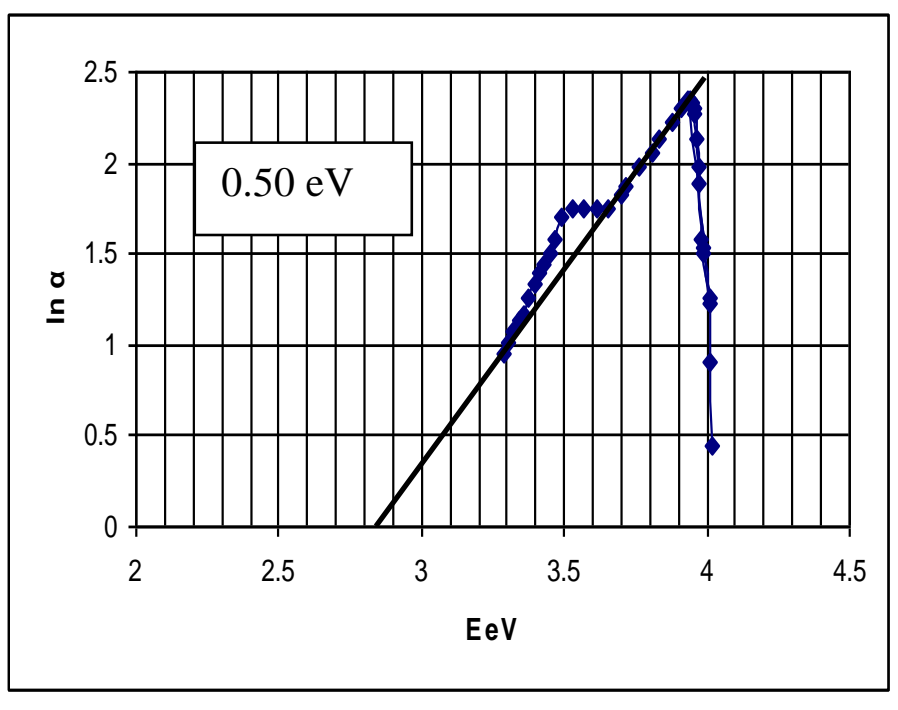

b $-\mathbf{3 ~ h r}$ 


\section{Qusay Kh. O. Al-dulamey}
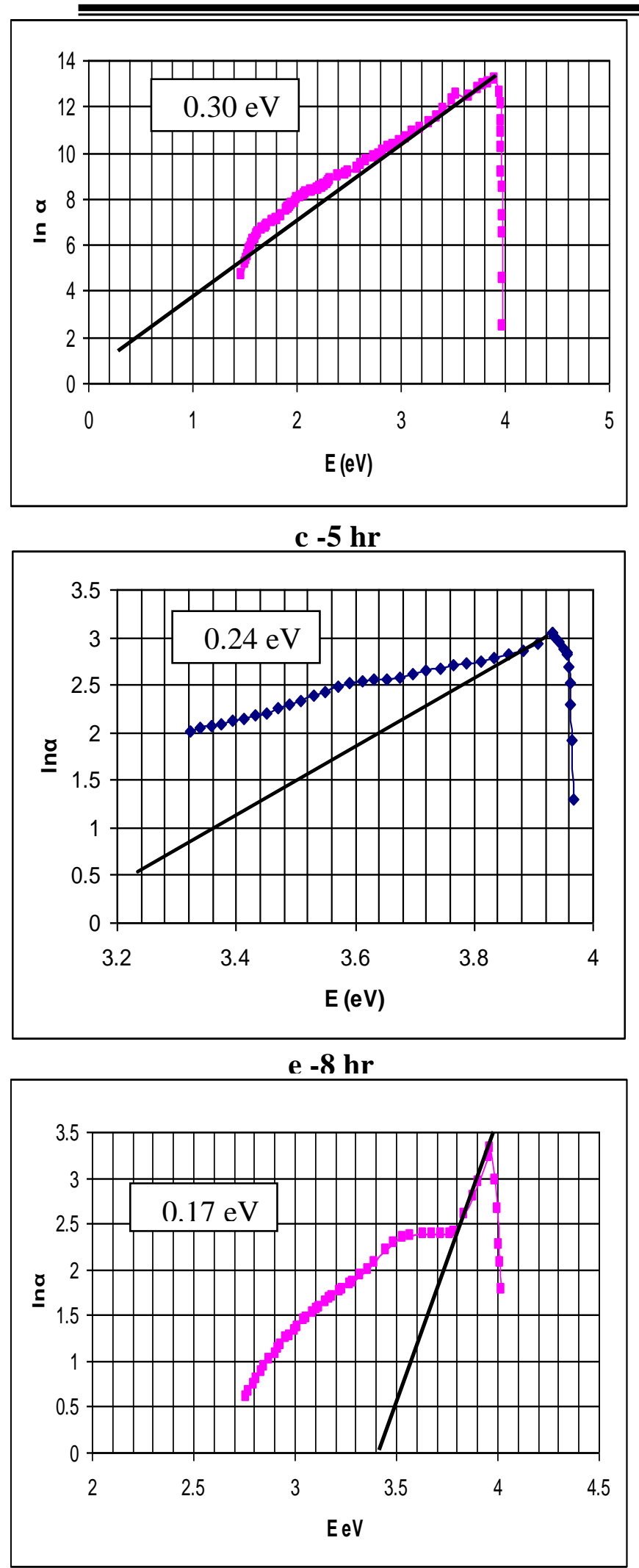

g-10 hr
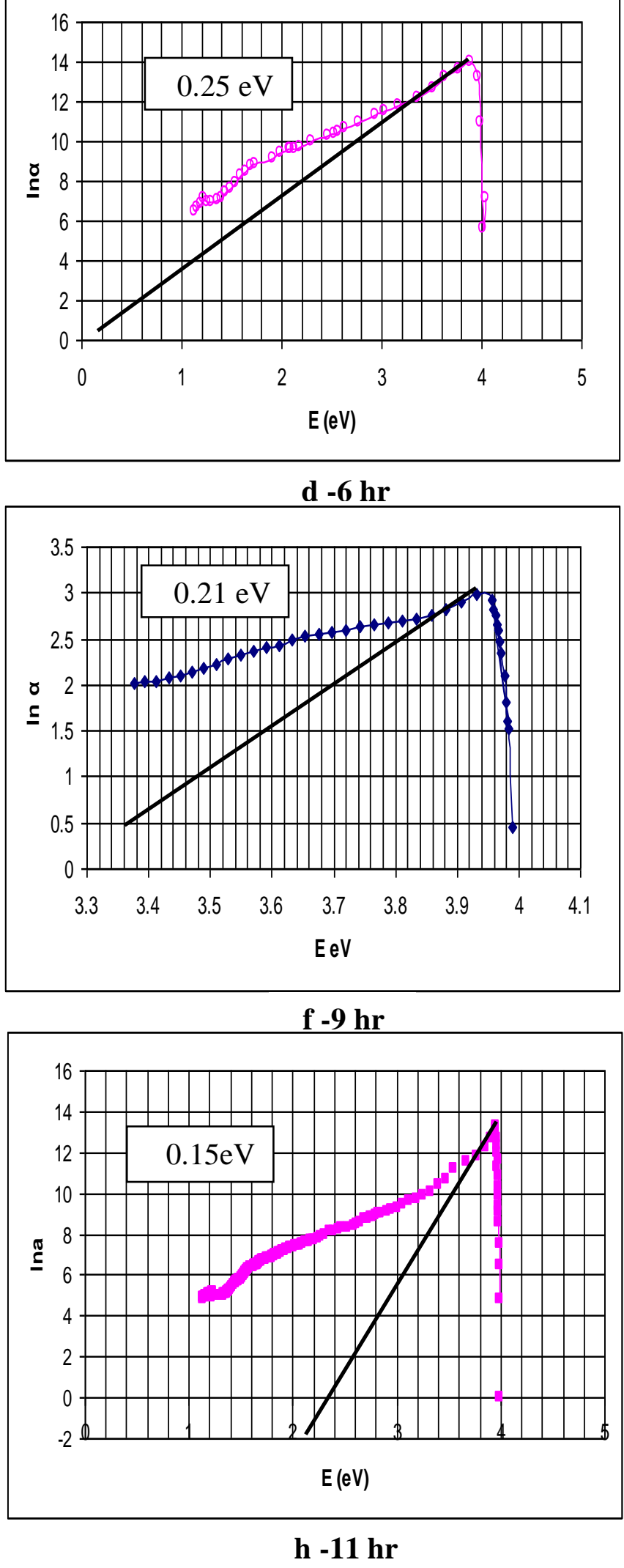

Fig. 2: Urbach energy for CR-39 which was irradiated with UV-radiation for a- 2 hr, b-3 hr, c 5 hr, d- 6 hr, e - 8 hr, f- 9 hr g, -10 hr, h- 11 hr 
The above relation was first proposed by Urbach (Urbach,1953) to describe the absorption edge in alkali halide crystals. Also, this relation has been found to hold for many amorphous materials. Eq. (2) has been modified to a more general form by (Sulaiman,2006)

$\alpha . h v=B\left(h v-E_{g}\right)^{n}$.

where $h v$ is the energy of the incident photons, energy gap $\left(E_{g}\right)$ is the value of the optical energy gap between the valence band and the conduction band, and $n$ is the power, which characterizes the electronic transition, whether it is direct or indirect during the absorption process in the K-space. Specially, $n$ is $1 / 2,3 / 2,2$ and 3 for direct allowed, direct forbidden, indirect allowed and indirect forbidden transitions, respectively

The factor $B$ depends on the transition probability and can be assumed to be constant within the optical frequency range. The usual method for the determination of the value of $E_{g}$ involves plotting $(\alpha h v)^{1 / n}$ against $(h v)$. Indirect transitions in many amorphous materials fit the case for $n=2$; for a direct transition a reasonable fit with $n=1 / 2$ is achieved. In the present study the most satisfactory results were obtained by plotting $(\alpha h v)^{1 / 2}$ and $(\alpha h v)^{2}$ as a function of photon energy $(h v)$ respectively, taking into account the linear portion of the fundamental absorption edge of the UV-Visible spectra (shown in Fig. 1). Such plots have been presented in Figs. (3:a,b,c,d,e,f,g,h) and (4:a-b-c-d-e-f-g-h), respectively. From extrapolating the straight parts of these relations to the $h v$ axis, indirect and direct band gaps have been determined for UV irradiated (different doses) CR-39 polymer and these different transition energies are displayed in Figs (3:a,b,c,d,e,f,g,h,4:a,b,c,d,e,f,g,h) and depicted in Table 1. This, in turn, clearly indicates the simultaneous existence of indirect and direct band gap in CR-39 polymer with decreasing tendency at higher UV-radiation dose. This result confirms that the irradiation produces faults in CR-39 polymer structure (band rupture, free radical, etc.) which increases the electronic disorder inducing the creation of a permit state in the forbidden (interdict) band or the deformation of the valence band (Zaki,2008).

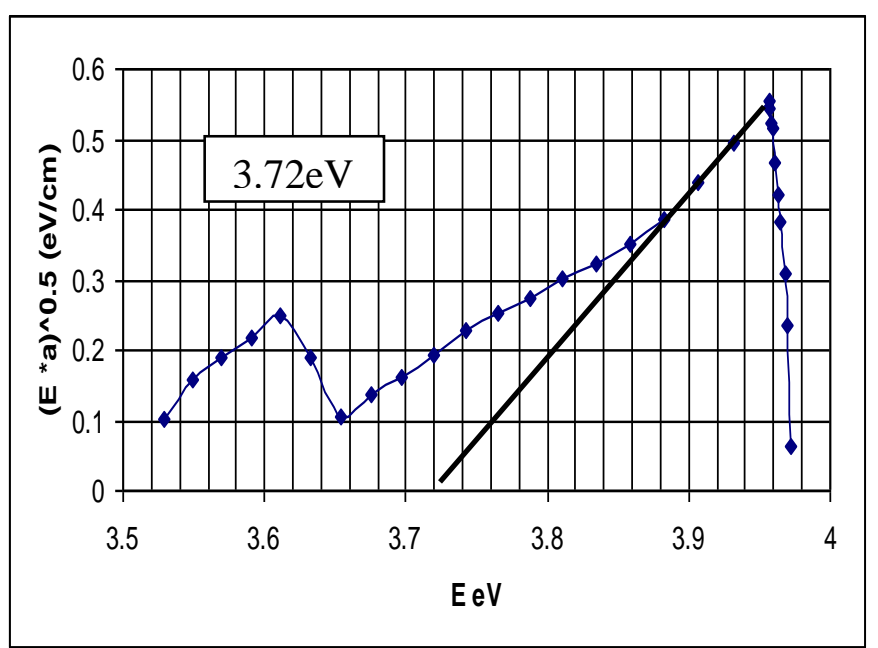

a $-2 \mathbf{h r}$

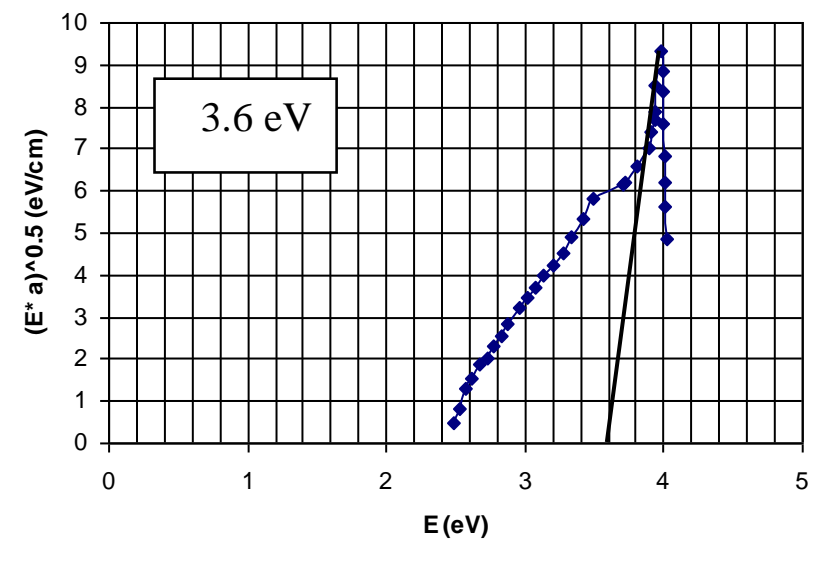

b $-3 \mathbf{h r}$ 

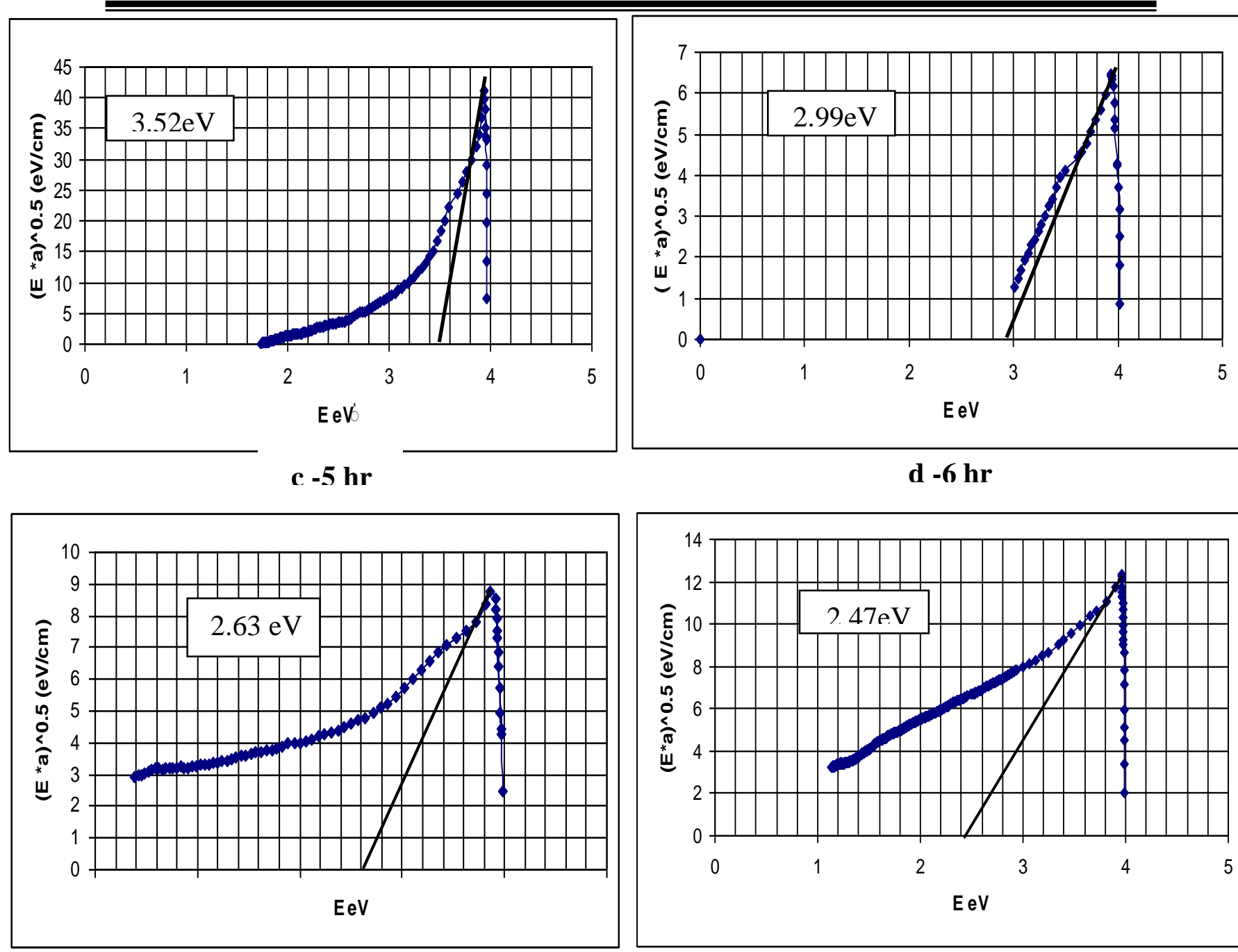

e- 8 hr

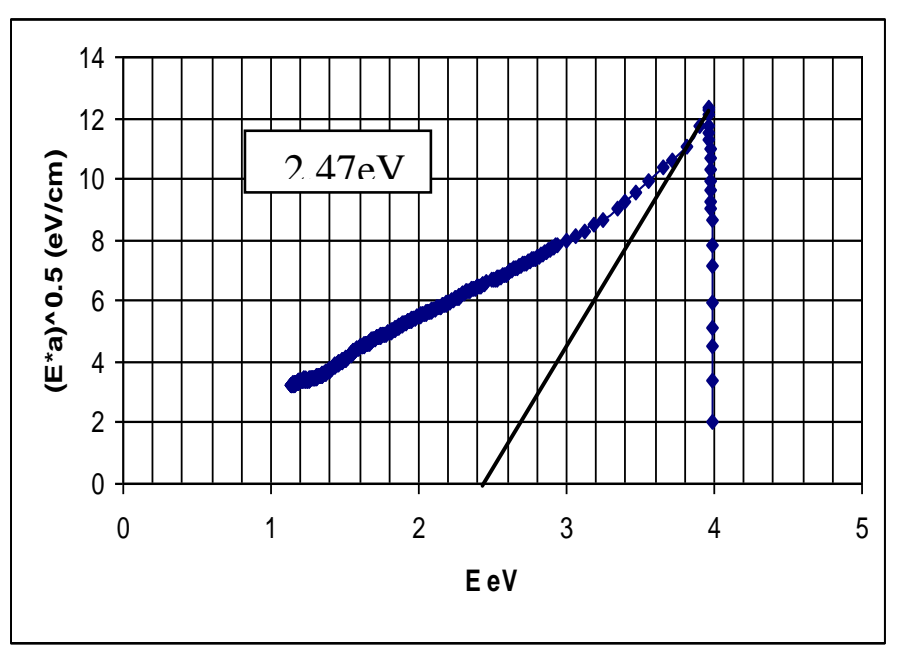

f - 9 hr

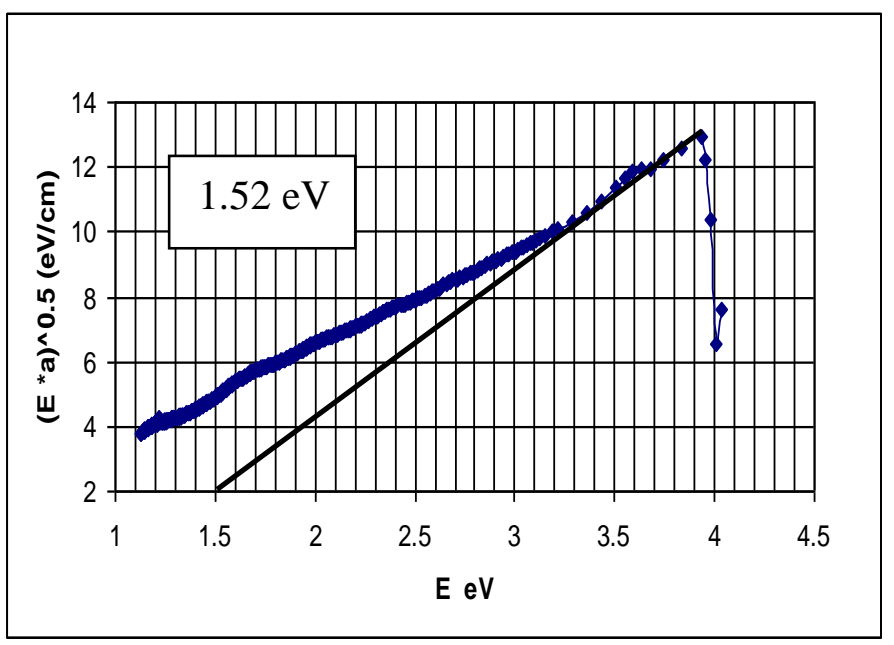

g- 10 hr

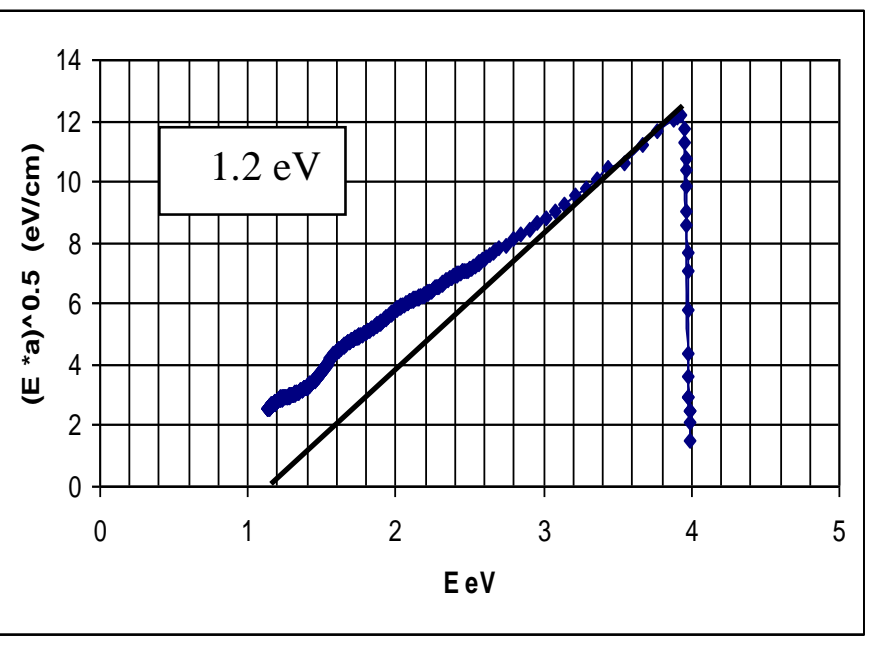

h- 11 hr

Fig.3: indirect energy gap for CR-39 which was irradiated with UV-radiation for a2 hr, b- 3 hr, c- 5 hr, d -6 hr, e- 8 hr, f- 9 hr, g- 10 hr, h-11 hr 


\section{Effect of UV-radiation on physical properties for CR-39 detector.}

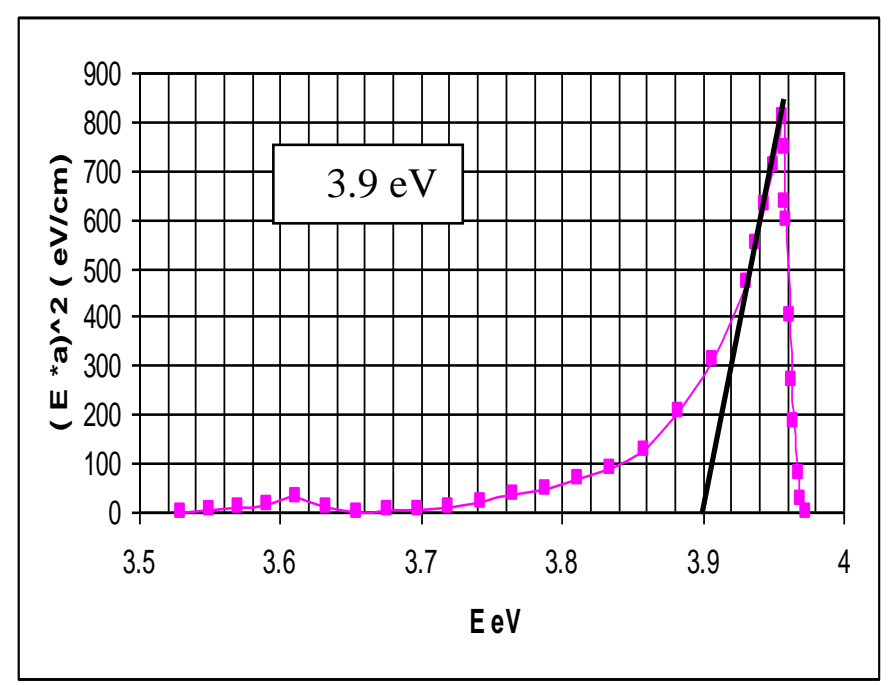

a -2 hr

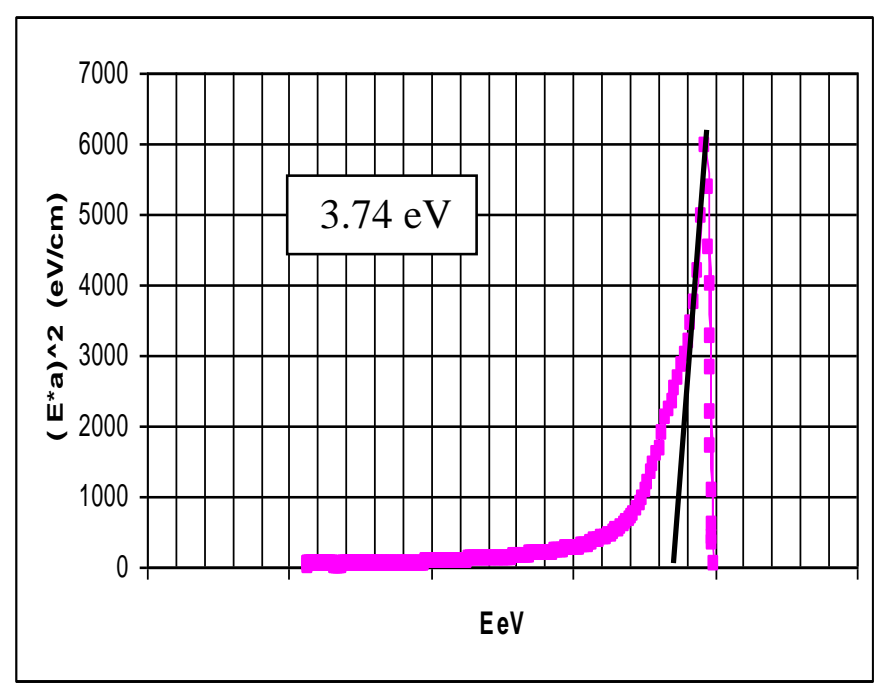

c $-5 \mathrm{hr}$

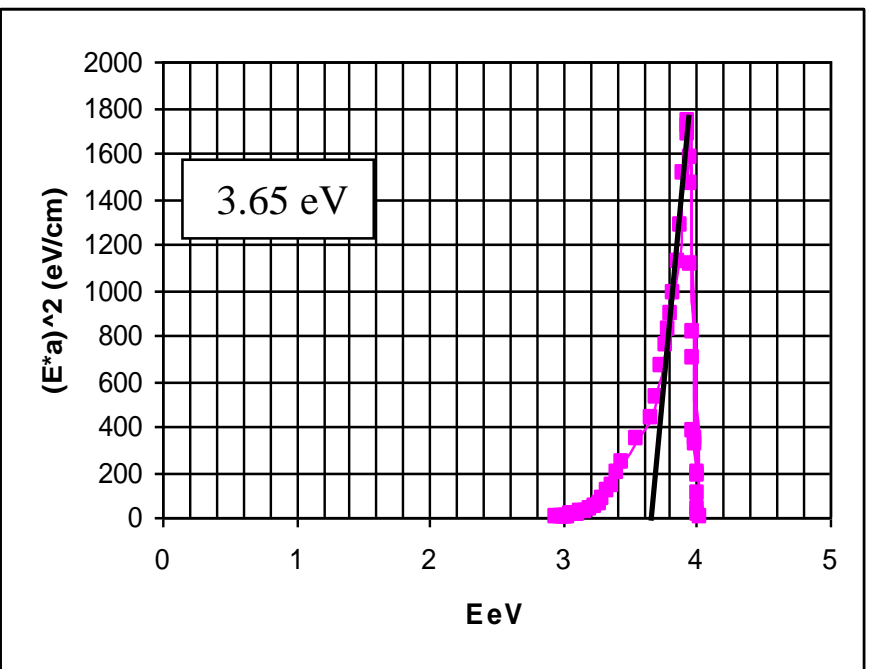

e $-8 \mathrm{hr}$

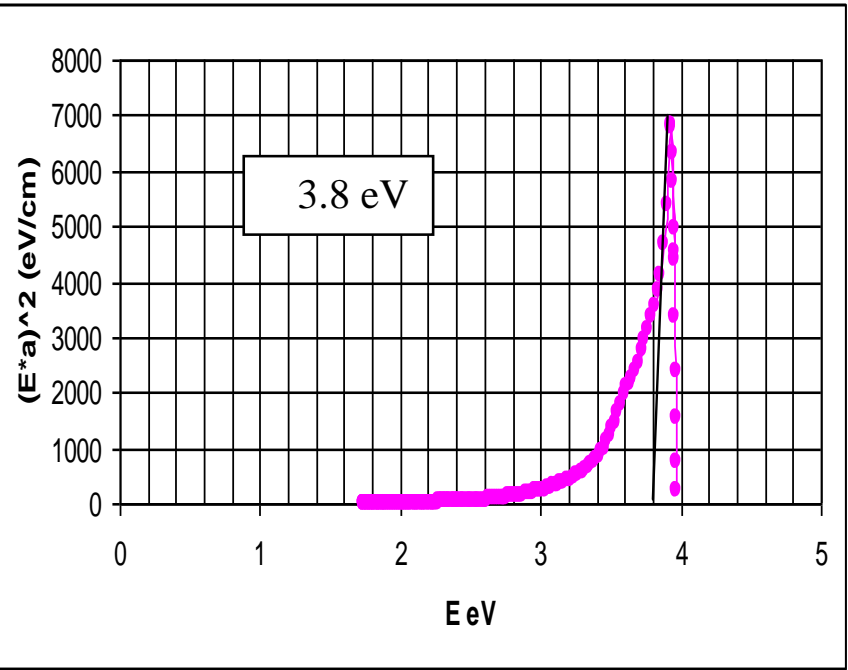

b -3 hr

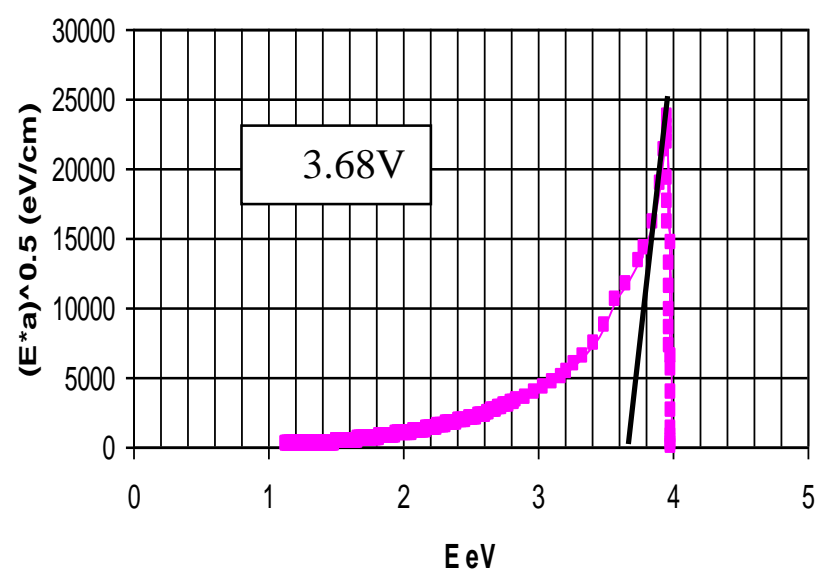

d $-6 \mathrm{hr}$

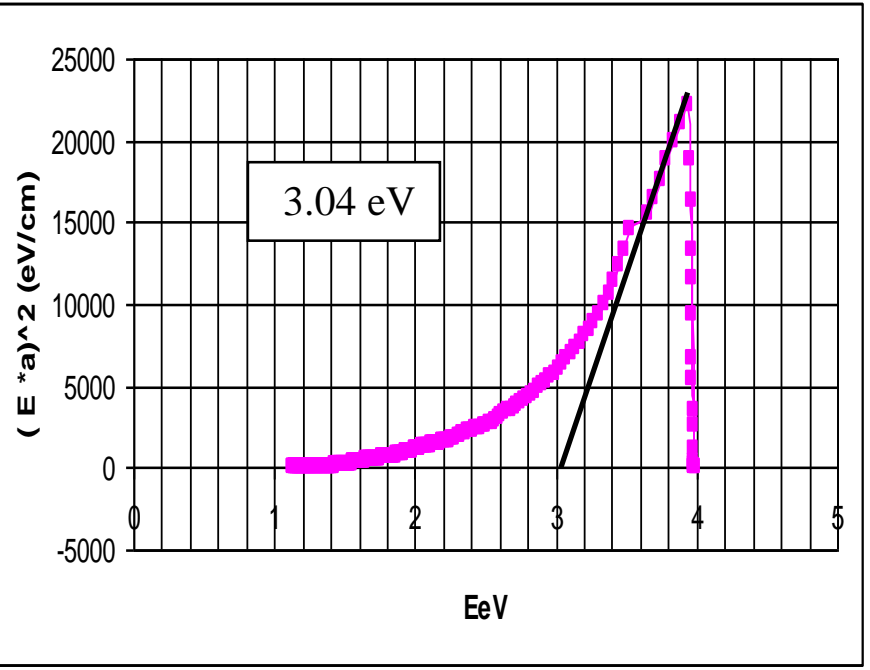

f $-9 \mathrm{hr}$ 


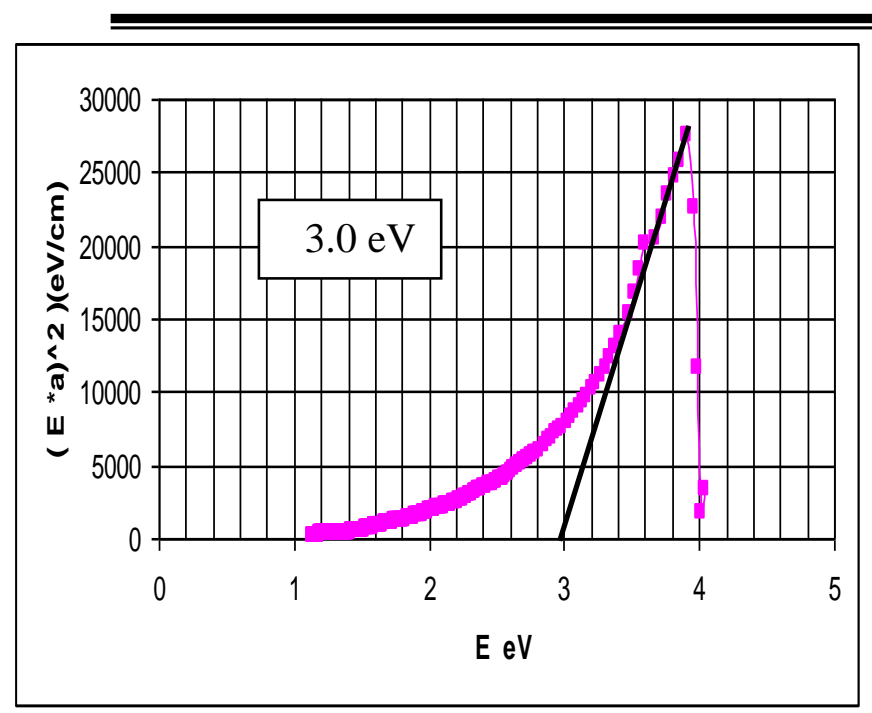

g - $10 \mathrm{hr}$

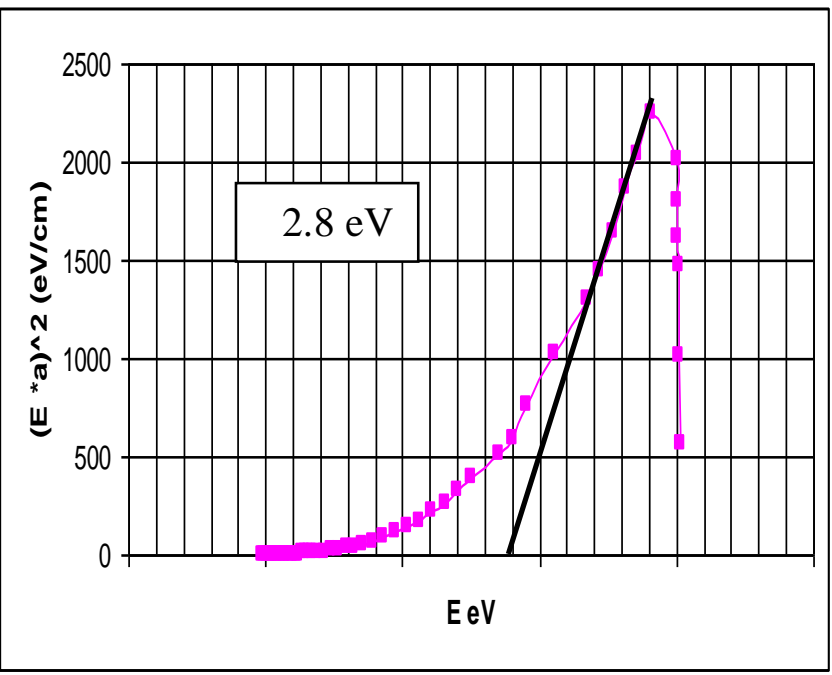

h -11 hr

Fig.4: direct energy gap for CR-39 which was irradiated with UV-radiation for a-2 hr, b- 3 hr, c- 5 hr, d -6 hr, e- 8 hr, f- 9 hr, g- 10 hr, h-11 hr

Furthermore, the values of indirect band gap have been found to be lower than the corresponding values for the direct band gap as shown in Figs $(3,4)$. The simultaneous existence of indirect as well as direct band gap in CR-39 polymer has rarely been reported (Migahed \& Zidan,2006), although such a coexistence of direct and indirect band gap have been observed in some other materials' (Tanu et al,2007)

The number of carbon atoms per conjugation length $N$ is given by (Zaki,2008) (Kumar et al,2009)

$N=2 \beta \pi / E_{g}$.

Here $2 \beta$ gives the band structure energy of a pair of adjacent $\pi$ sites.The value of $\beta$ is taken to be $\sim 2.9 \mathrm{eV}$ as it is associated with $\pi \rightarrow \pi^{*}$ optical transitions in $-\mathrm{C}=\mathrm{C}$ - structure. As the shift of the absorption edge can be attributed to an increase of the conjugation length without formation of new lengthy linear conjugated structures, Eq. (4) is applied in the present study.

Finally the exposure time of CR-39 irradiated with UV-radiation has converted to radiation dose by multiplying with converter factor $(9.524$ $\mathrm{erq} / \mathrm{mm}^{2}$.sec) which was used from (AL-Jomaily,2009) for the same wave length of UV-radiation in this work. and fixed in Table 1.

When the UV- radiation was striking CR-39 detector, the heat generated from this processing more than heat generated if IR radiation passed from the same detector for the same case because high absorption edge obtained at wave length of UV-radiation $(254 \mathrm{~nm})$ which was corresponding to the band structure energy of band pair of carbon $-\mathrm{c}=\mathrm{c}-\sim$ 
$2.9 \mathrm{eV}$, Thus the Urbach energy was determined in this work near to the Urbach energy computed in previous study spically (Prasher et al,2009 ((Zaki,2008) as shwn in (Table.2) because the Urbach energy depend on the heat generated from the band and the type of impure material in base material (Bozhko et al,2002).

Table 1. Computing UV-radiation dose, Band energy gap (eV), Urbach energy (eV) and $\mathbf{N}$ (number of carbon atom)

\begin{tabular}{|c|c|c|c|c|c|c|}
\hline \multirow[t]{2}{*}{$\begin{array}{c}\text { UV exposure } \\
\text { time/hr }\end{array}$} & \multirow[t]{2}{*}{$\begin{array}{c}\text { UV-radiation } \\
\text { dose } \\
\left(\mathrm{erq} / \mathbf{m m}^{2}\right)\end{array}$} & \multicolumn{2}{|c|}{$\begin{array}{c}\text { Band energy } \\
\text { gap }(\mathrm{eV})\end{array}$} & \multirow[t]{2}{*}{$\begin{array}{c}\text { Urbach } \\
\text { energy } \\
(\mathrm{eV})\end{array}$} & \multicolumn{2}{|c|}{$\begin{array}{c}\mathbf{N} \\
\text { (number of } \\
\text { carbon atom per } \\
\text { conjugation } \\
\text { length) }\end{array}$} \\
\hline & & indirect & direct & & indirect & direct \\
\hline 2 & 68572.8 & 3.72 & 3.9 & 0.10 & $\sim 5$ & $\sim 5$ \\
\hline 3 & 102859.2 & 6 & 3.8 & 0.50 & $\sim 6$ & $\sim 5$ \\
\hline 5 & 171432 & 3.52 & 3.74 & 0.30 & $\sim 6$ & $\sim 5$ \\
\hline 6 & 205718.4 & & 3.68 & 0.25 & $\sim 7$ & $\sim 5$ \\
\hline 8 & 274291.2 & 2.63 & 3.65 & 0.24 & $\sim 8$ & $\sim 6$ \\
\hline 9 & 308577.6 & 2.47 & 3.04 & 0.21 & $\sim 8$ & $\sim 6$ \\
\hline 10 & 342864 & 1.52 & 3.0 & 0.17 & $\sim 12$ & $\sim 7$ \\
\hline 11 & 377150.4 & 1.2 & 2.8 & 0.15 & $\sim 16$ & $\sim 7$ \\
\hline
\end{tabular}

Table 2. Comparitive present work with prevous studies.

\begin{tabular}{|c|c|c|c|c|c|c|c|}
\hline \multirow{2}{*}{ Researcher } & \multirow{2}{*}{ Detector } & \multirow{2}{*}{ Radiation } & \multirow{2}{*}{$\begin{array}{c}\text { Urbach } \\
\text { energy eV }\end{array}$} & \multicolumn{2}{|c|}{$\begin{array}{c}\text { Band energy gap } \\
\text { eV }\end{array}$} & \multicolumn{2}{|c|}{$\begin{array}{l}\text { N(number of } \\
\text { (carbon atom }\end{array}$} \\
\hline & & & & direct & indirect & direct & indirect \\
\hline $\begin{array}{c}\text { Singh\& } \\
\text { Samra,2007 }\end{array}$ & CR-39 & Proton & . & 4.36-3.15 & $\cdots .$. & 5 & ........... \\
\hline $\begin{array}{c}\text { Ramola } e t \\
\text { al,2008 }\end{array}$ & CR-39 & Neutron & $0.74-0.29$ & $3.42-1.35$ & $4.90-2.30$ & $4-8$ & 5-13 \\
\hline $\begin{array}{c}\text { Prasher et } \\
a l, 2009\end{array}$ & CR-39 & IR & 27 & $5.2-2.30$ & ........... & & ....................... \\
\hline Zaki,2008 & CR-39 & Gamma- ray & $0.61-0.53$ & $4.2-2.7$ & 3.6-1.9 & $4-7$ & $5-9$ \\
\hline $\begin{array}{c}\text { Present } \\
(\text { Work,2010) }\end{array}$ & CR-39 & $\begin{array}{l}\text { UV - } \\
\text { radiation }\end{array}$ & $0.5-0.10$ & $3.9-2.8$ & $3.72-1.2$ & $5-7$ & $5-16$ \\
\hline
\end{tabular}

The Urbach's energy sharply decreasing with increasing UV-radiation dose as Fig. 5.This sharp decrease indicates the irregularization of the band gap energy level; furthermore this is due to amorphous nature of CR-39 polymer. The decrease in band gap energy attributes to the decrease in the resistivity of CR-39. This means that there is change in the structural characteristics of CR-39 as a result of UV- irradiation (Kumar et al,2009). It may accounts for the scission of the polymer chain and formation of free radicals. 


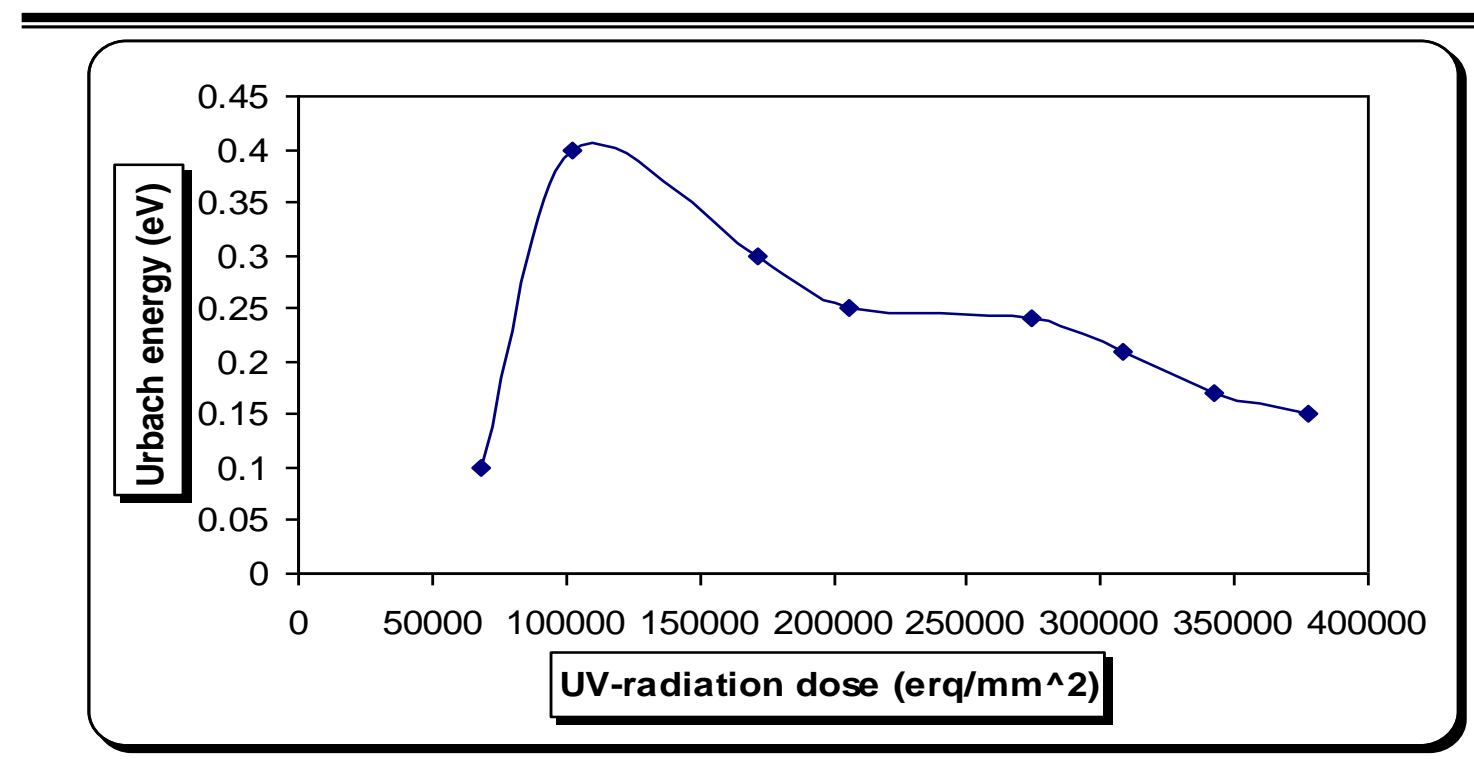

Fig. 5 :Calibration curve between Urbach energy (eV) with UV-radiation dose $\left(\mathrm{erq} / \mathrm{mm}^{2}\right)$

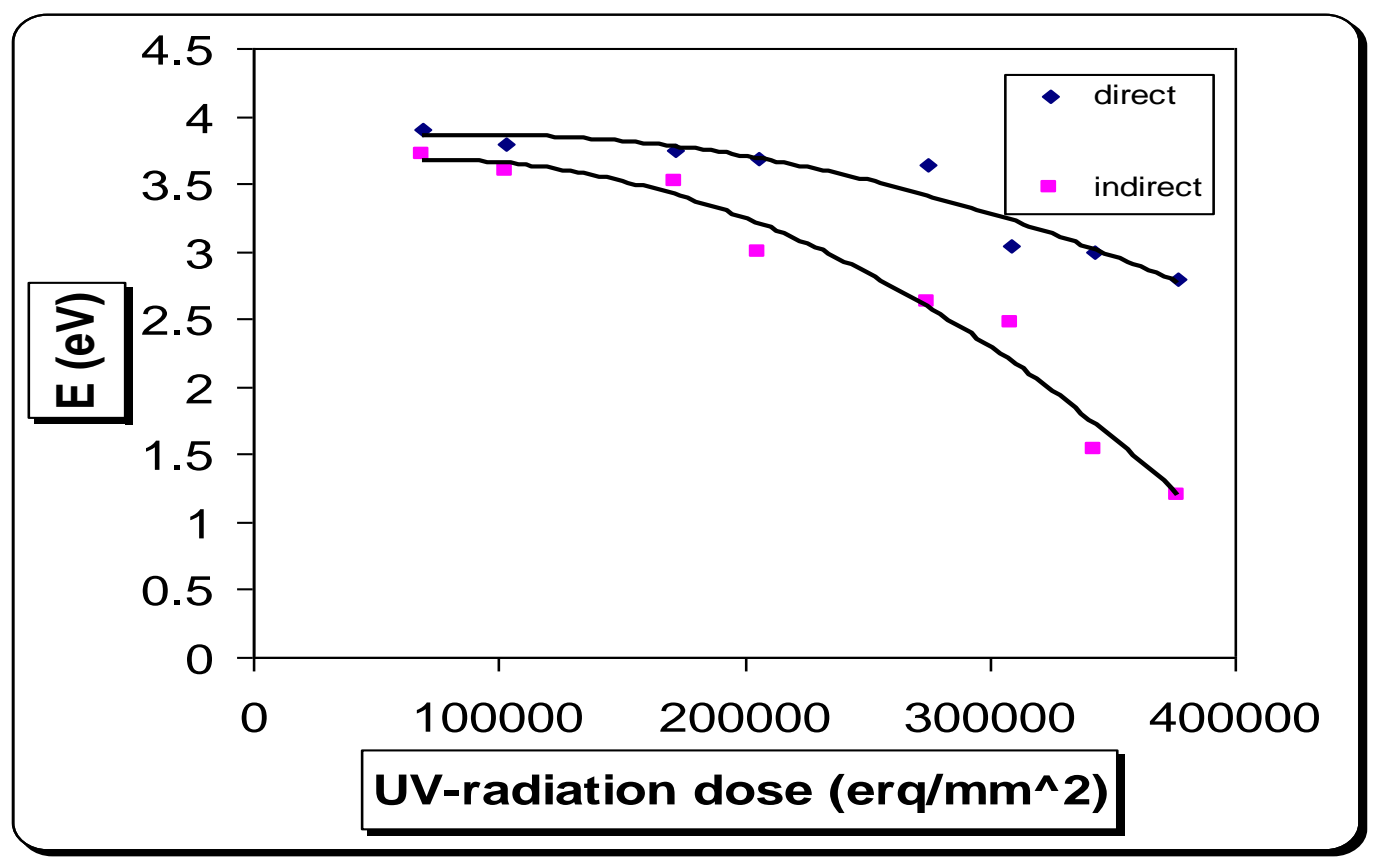

Fig. 6: Calibration curve between band energy (eV) with UV-radiation dose $\left(\mathrm{erq} / \mathrm{mm}^{2}\right)$

It is observed that thereis a decreasing trend of energy gap with increasing UV-radiation dose Fig.6.

This is due to the carbon enriched domains created in polymers during irradiation. In the studied range of wavelength the absorption bands are associated with $\pi \rightarrow \pi^{*}$ electronic transition. The excitation of $\pi$ electron require smaller energy and hence, transition of this type occurs at longer 
wavelength. In the high absorption region where absorption is associated with interband transition (Zaki,2008) (Kumar et al,2009).

\section{Conclusion}

1- increasing UV-radiation dose lead to decreasing the direct and indirect of energy gap for CR-39 detector, Thus the electrical conductivity $(\sigma)$ increase.

2- The atomic number (N) for CR-39 increase with increasing UVradiation dose.

3- The crystalline structure of CR-39 detector was changing with increasing UV-radiation dose because to the physical and chemical properties had changed.

4- The Urbach's energy $\left(E_{u}\right)$, ecxatation energy of electron, sharply decreasing with increasing UV-radiation dose.

\section{Reference}

1) Urbach F., (1953), Phys. Rev. 92, page 1324.

2) Aburjared, F., Islam, MA., Abuabdoun, I., Kham, MA., (2000), Ultraviolet and laser irradiation effects on various batches of CR-39, Pergamon-elsevier science ltd, nuclear tracks and radiation measurement; pp: 135-139; Vol:19.

3) Mark Fox M., (2001), Optical Properties of Solids, Oxford University Press Inc., New York.

4) Bozhko, V. V., Halyan, V. V., Parasyuk, O. V., (2002), Urbach.s edge of glassy $\mathrm{HgSe}-\mathrm{GeSe} 2$ alloys: static disorder and temperature dependence of optical absorption,Department of Solid State Physics, Volyn State University, 13 prospect Voli, 43009 Lutsk, Ukraine, Semiconductor Physics, Quantum Electronics \& Optoelectronics. 2002. V. 5, N 2. pp. 163-169.

5) Migahed, M. D., Zidan H. M., (2006),Current Applied Physics 6, 91.

6) Sulaiman., I. R. M., (2006), effect of annealing in the optical absorbance of PM-355 nuclear track detector radiated by alpha particale, theses, University of Mosul, College of education,page 17.

7) Sharma, T., Aggarwal, S., amdKumar, Mittal, V. K., Kalsi, P. C., Manchanda, V.K. S., (2007), Effect of gamma irradiation on the optical properties of CR-39 polymer, Mater Science Vol:42.pp.1127-1130. 
8) Tanu Sharma, Sanjeev Aggarwal, Shyam Kumar, V. K. Mittal, P. C. Kalsi, and Manchanda V. K. J., (2007) Mater Sci. 42, 1127.

9) Singh L., Samra K. S., (2007), V Surface and Bulk Structure Characterization of Proton (3 MeV) Irradiated Polycarbonate, Deptt. of Physics, Guru Nanak Dev University, Amritsar, Punjab, India, Published in: Journal of Macromolecular Science, Part B, Volume 46, Issue 5. DOI: 10.1080/00222340701457493.

10) Zaki, M. F., (2008), Gamma-Induced Modification on Optical Band Gap of CR-39 SSNTD, Journal of 558 Brazilian Physics, vol. 38, no. 4, December, pp.1-6.

11) Tse K.C.C., Nikezic D., Yue K. N.,(2008), Effects of UVC irradiation on alpha-particle track parameters in CR-39, Department of physics and material science, Honh Kong University, Sicence Direct Journal Vol.43.PP.98-101.

12) Ramola, R. C., Chandra, S., Negi, A., Rana, J. M. S., Annapoorinal, S., Sonkawade, R. G., Kulrlya, P.K. and Srivastava, A., (2008), Study of optical band gap, carbonaceous clusters and structuring in CR-39 and PET polymers irradiated by $100 \mathrm{MeV} \mathrm{O7+} \mathrm{ions,} \mathrm{Physics} \mathrm{B:} \mathrm{condensed}$ matter, Volume 404, Issue 1, 15 pages 26-30.

13) Kumar, V., Sonkawade, R. G., Dhaliwal, A.S., Mehra, R., (2009), Study of Neutron Induced Modification on Optical Band Gap of CR-39 Polymeric Detector, Asian Journal of Chemistry Vol. 21, No. 10, pp.279-283.

14) Prasher S., Narwal S., Rana, M., M., Kumar, M. M.,(2009), A Comparative Study on the Influence of IR Radiations to Some Polymers, Asian Journal of Chemistry Vol. 21, No. 10, pp.216-219

15) AL-Jomaily., F. M. Ali F., (2009), Electromagnetic radiation dosimety using nuclear track and determination of their intrinsic efficiencies with invocation computer image processing in determination of nuclear parameter pp.61. 